\title{
Effect of Leptin on Neutrophils Phagocytosis and Lymphocytes Apoptosis Challenge by Listeria monocytogenes and Escherichia coli
}

\author{
Amir Morshedi ${ }^{1}$, Sayyed Hamid Zarkesh-Esfahani ${ }^{1,{ }^{*}}$, Mohaddeseh Behjati ${ }^{2}$ \\ ${ }^{1}$ Department of Biology, Faculty of Science, University of Isfahan, Isfahan, IR Iran \\ 2 Isfahan Cardiovascular Research Institute, Isfahan Universityof Medical Sciences, Isfahan, IR Iran \\ ${ }^{*}$ Corresponding author: Sayyed Hamid Zarkesh-Esfahani, Department of Biology, Faculty of Sciences, University of Isfahan, Hezar Jerib Street, Isfahan, 81746-73695, IR Iran. Tel: +98- \\ 3117932473, Fax:+98-3117932456, E-mail:s.h.zarkesh@sheffield.ac.uk
}

Received: May 17, 2012; Revised: October 17, 2012; Accepted: October 24, 2012

\begin{abstract}
Background: Leptin is a cytokine/hormone produced mainly by the adipocytes which regulates the body weight. The normal level of Leptin is required for optimal immune system function, and high leptin levels are shown to affect the Th1-Th2 balance. Leptin is able to stimulate monocytes, dendritic cells and Neutrophils.

Objectives: The aim of this study was to evaluate the effect of leptin on neutrophils phagocytosis and lymphocytes apoptosis stimulated by Listeria monocytogenes and Escherichia coli.

Materials and methods: Blood samples were taken from healthy volunteers and were treated with either leptin or PBS in presence or absence of L. monocytogenes or E. coli. In order to evaluate the activation of neutrophils and their phagocytosis activity, the expression of CD11b by these cells were assessed using flow cytometry. The ability of leptin to induce apoptosis in lymphocytes was investigated using Annexin V and PI staining method by flow cytometry.

Results: Our data demonstrates that leptin is able to induce CD11b expression on neutrophils but this induction is significantly less than L. monocytogenes. Indeed, cells treated with leptin had lower amounts of apoptosis compared with untreated cells. The highest amount of apoptosis was seen in cells treated with L. monocytogenes vs. E. coli. Leptin can be used as a potent agent for induction of effective bacterial phagocytosis and lymphocytic apoptosis in cases with sever immune-deficiency.

Conclusions: The Leptin can also be used for the treatment of severe and intractable L. monocytogenes and E. coli infection.
\end{abstract}

Keywords: Leptin; Neutrophil; Lymphocyte; Apoptosis; Phagocytosis; Listeria monocytogenes; Escherichia coli

\section{Background}

Leptin, an adipose-derived hormone/cytokine, is a powerful defending element of Immune system against bacterial infections $(1,2)$. Congenital leptin deficiency causes immune dysfunction in affected newborns and is associated with early childhood death due to overwhelming infections $(2,3)$. Administration of leptin to leptin deficient mice has been shown to make them resistant to Klebsiella pneumonia (4). Leptin stimulates the proliferation of peripheral monocytes in-vitro and leads to enhanced expression of CD11b, a marker of neutrophilic phagocytosis, on the surface of monocytes $(5,6)$. Despite the potent role of leptin in immune system functions, its interaction with diverse pathogenic bacteria, especially intracellular bacteria which potentially escape from phagocytosis by immune cells, is not well understood.

Listeria monocytogenes is an intracellular pathogen which causes various diseases such as fulminant Listeriosis, meningitis, endocarditis and disseminated bactere- mia mainly in immune-deficient patients and neonates $(2,7,8)$. Listeriolysin secreted by L. monocytogenes, inhibits the procedure of macrophage-mediated processing of bacterial antigens $(9,10)$. Indeed, L. monocytogenes destructs cell membranes especially phagosomemembranes thatleads to intracellular bacterial growth (9, 10). L. monocytogenes potently induces apoptosis in T-cell lymphocytes through both caspase-dependent and independent pathways $(11,12)$. After phagocytosis of $L$. monocytogenes by antigen-presenting cells (APC), the produced Listeriolysin $\mathrm{O}$ potentiates its cytosolic growth which leads to APC death through inflammatory mediators (13, 14). Due to the diverse effects of this pathogen on induction of apoptosis and phagocytosis of immune cells and its ability to escape from immune system, L. monocytogenes was selected to be used in this study (8).

\section{Objectives}

The aim of this study was to investigate the role of leptin Implication for health policy/ practice/ research/medical education:

Leptin is a cytokine/hormone produced mainly by the adipocytes which regulates the body weight. The normal level of Leptin is required for optimal immune system function, and high leptin levels are shown to affect theTh1-Th2 balance. Leptin is able to stimulate monocytes, dendritic cells and neutrophils. Thus, the aim of this study was to evaluate the effect of leptin on neutrophils phagocytosis and lymphocytes apoptosis stimulated by Listeria monocytogenes and Escherichia Coli.

Copyright (c) 2013, Ahvaz Jundishapur University of Medical Sciences; Licensee Kowsar Ltd. This is an Open Access article distributed under the terms of the Creative Commons Attribution License (http://creativecommons.org/licenses/by/3.0), which permits unrestricted use, distribution, and reproduction in any medium, provided the original work is properly cited. 
Morshedi A et al.

in induction of phagocytosis and apoptosis on cells of immune systems infected by L. monocytogenes. Since Escherichia coli has been shown to enhance the CD11b expression on the surface of neutrophils triggered by the presence of FMLP, E. coli was used as a control bacteria in this study (15).

\section{Materials and Methods}

10-15 mL of heparinized blood were drawn from healthy male volunteers (age 21-34) after they have signed informed contest form. The study was approved by local ethics committee. To evaluate the blood neutrophils, 100 $\mu \mathrm{L}$ of blood was transferred into each sterile flow cytometry tube. Samples were treated differently as listed in Table 1. L. monocytogenes PTCC1295 and non-pathogenic E. coli were grown in TSA/TSB (Merck, Germany) culture medium supplemented with $1 \%$ yeast extract (Merck, Germany) and 10\% human blood and Nutrient agar (Merck, Germany )culture medium, respectively. L. monocytogenes.

Table 1. Different Treatments of Blood Samples for Assessment of Cd11b Expression

\begin{tabular}{|c|c|}
\hline Treatments Agent(s) & Staining Antibody \\
\hline PBS & Without antibody \\
\hline PBS & FITC-conjugated murine IgG1 monoclonal antibody \\
\hline PBS & FITC-conjugated murine anti-human CD11b monoclonal antibody \\
\hline E. coli & Without antibody \\
\hline E. coli & FITC-conjugated murine IgG1 monoclonal antibody \\
\hline E. coli & FITC-conjugated murine anti-human CD11b monoclonal antibody \\
\hline L. monocyogenes & Without antibody \\
\hline L. monocyogenes & FITC-conjugated murine IgG1 monoclonal antibody \\
\hline L. monocyogenes & FITC-conjugated murine anti-human CD11b monoclonal antibody \\
\hline Leptin $+E$. Coli & Without antibody \\
\hline Leptin $+E$. Coli & FITC-conjugated murine IgG1 monoclonal antibody \\
\hline Leptin $+E$. Coli & FITC-conjugated murine anti-human CD11b monoclonal antibody \\
\hline Leptin + L. monocyogenes & Without antibody \\
\hline Leptin + L. monocyogenes & FITC-conjugated murine IgG1 monoclonal antibody \\
\hline Leptin + L. monocyogenes & FITC-conjugated murine anti-human CD11b monoclonal antibody \\
\hline
\end{tabular}

Table 2. Different Treatments of Blood Samples for Assessment of Apoptosis

\begin{tabular}{|c|c|}
\hline Treatments & Staining agent \\
\hline No treatment & FITC-conjugated Annexin V \\
\hline No treatment & PI \\
\hline Doxorubicin & FITC-conjugated Annexin V \\
\hline Doxorubicin & PI \\
\hline E. Coli & FITC-conjugated Annexin V \\
\hline E. Coli & PI \\
\hline L. monocyogenes & FITC-conjugated Annexin V \\
\hline L. monocyogenes & PI \\
\hline Leptin $+E$. coli & FITC-conjugated Annexin V \\
\hline Leptin $+E$. coli & PI \\
\hline Leptin + L. monocyogenes & FITC-conjugated Annexin V \\
\hline Leptin+L. monocyogenes & PI \\
\hline $\begin{array}{l}\text { was used for stimulation of PBMCs (Peripheral Blood } \\
\text { Mononuclear cells) compared with E. coli as a control. For } \\
\text { bacterial challenge, } 10^{8} \text { bacteria were added to } 106 \text { cell }\end{array}$ & $\begin{array}{l}\text { (multiplicity of infection=100). } \\
\text { Leptin (R\&D systems, USA) was used at a concentration } \\
\text { of } 250 \mathrm{ng} / \mathrm{mL} \text {. After treatments, tubes were incubated in }\end{array}$ \\
\hline
\end{tabular}


thermomixer for $10 \mathrm{~min}$ at $37^{\circ} \mathrm{C}$ and incubation was carried out for 3 hours. Cells were incubated with $5 \mu \mathrm{L}$ of listed antibodies for $20 \mathrm{~min}$ at $40^{\circ} \mathrm{C}$ in dark. Then, RBCs were lysed using RBC lysis buffer (DAKO 53350, Germany). The neutrophilsCD11b expression, as anactivity and phagocytosismarker, was evaluated using flow cytometry (Partec PAS, Germany) after staining with FITC-conjugated murine anti-human CD11b monoclonal antibody (Serotec, England). FITC-conjugated murine IgG1 monoclonal antibodies (Serotec, England) were used as staining control antibody. Data were analyzed using Flow Max software (Partec, Germany). All experiments were repeated 15 timesFor assessment of apoptosis, $10 \mathrm{~mL}$ of blood was used for isolation of mononuclear cells (PBMCs) from peripheral blood using Histopaque (Sigma A6929, Germa- ny) centrifuged at $400 \mathrm{~g}$ for $30 \mathrm{~min}$ according to manufacturer's recommendations.

After gentle mixing of isolated peripheral blood mononuclear cells with phosphate buffer saline (PBS, CMG Iran), cells were centrifugated at $250 \mathrm{~g}$ for $10 \mathrm{~min}$. Then, cells were transferred into RPMI-1640 culture media (Sigma R8755, Germany) and were washed twice. Isolated PBMCs were counted using improved Neobarhaemocytometer. To confirm and assess the presence of T-lymphocyte, cells were labeled with anti-human CD3-antibody (BD Pharmingen, USA) and were counted by flow cytometry.

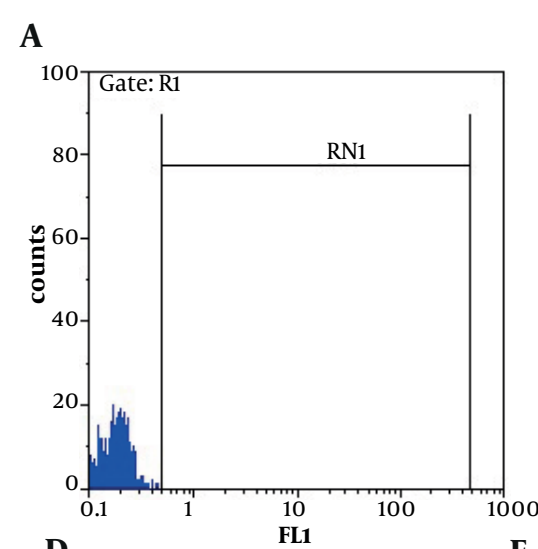

D

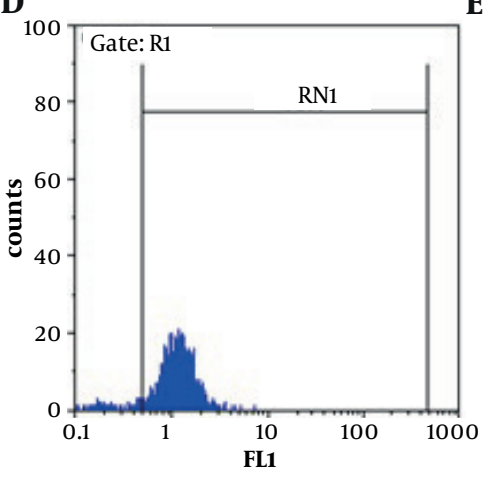

B
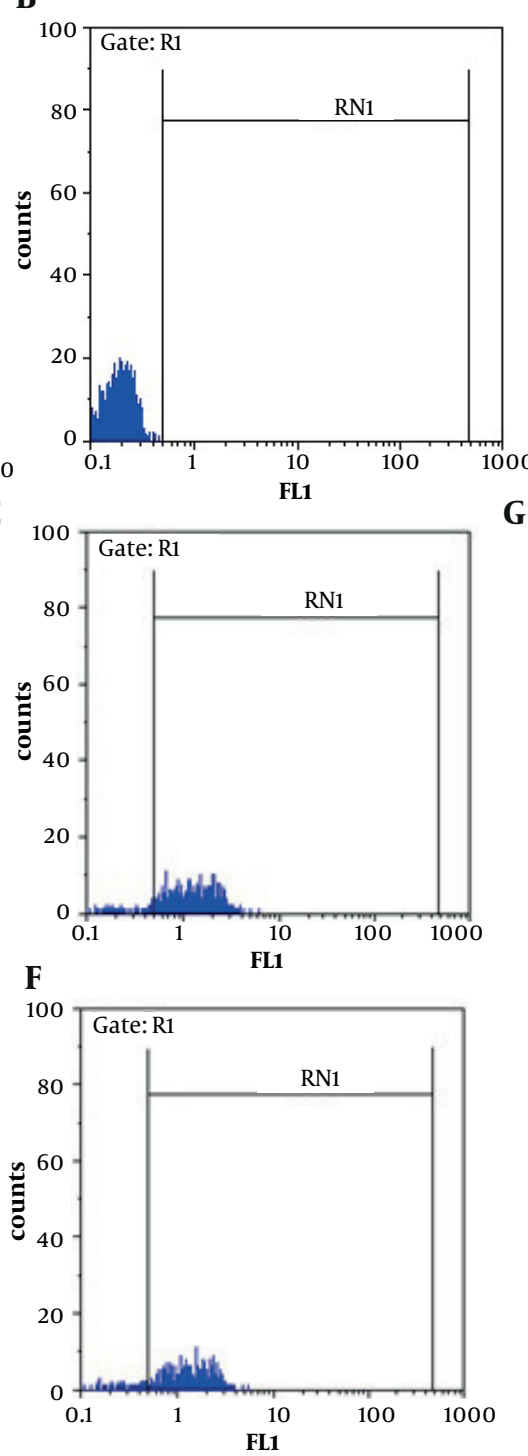

C
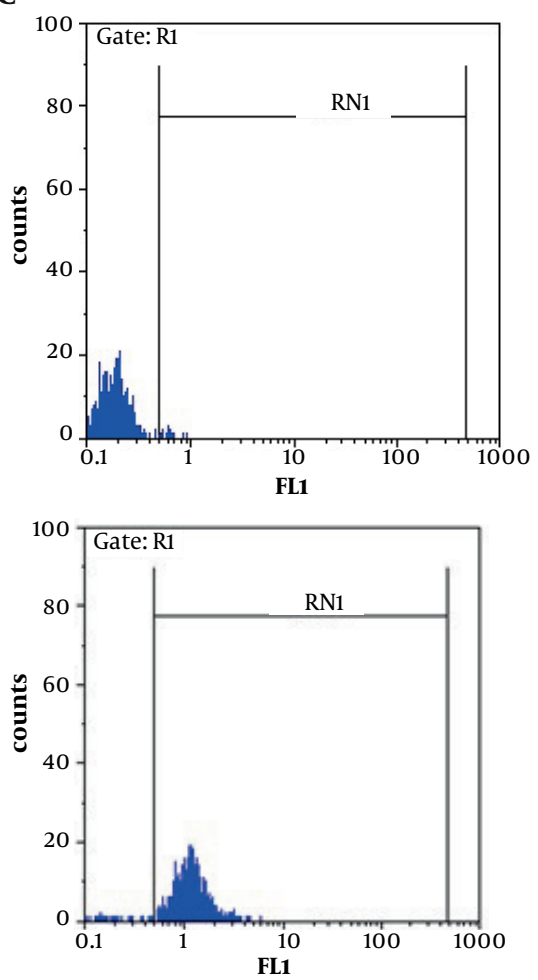

Figure 1. Mean-X Fluorescence in Neutrophils After Various Treatments 


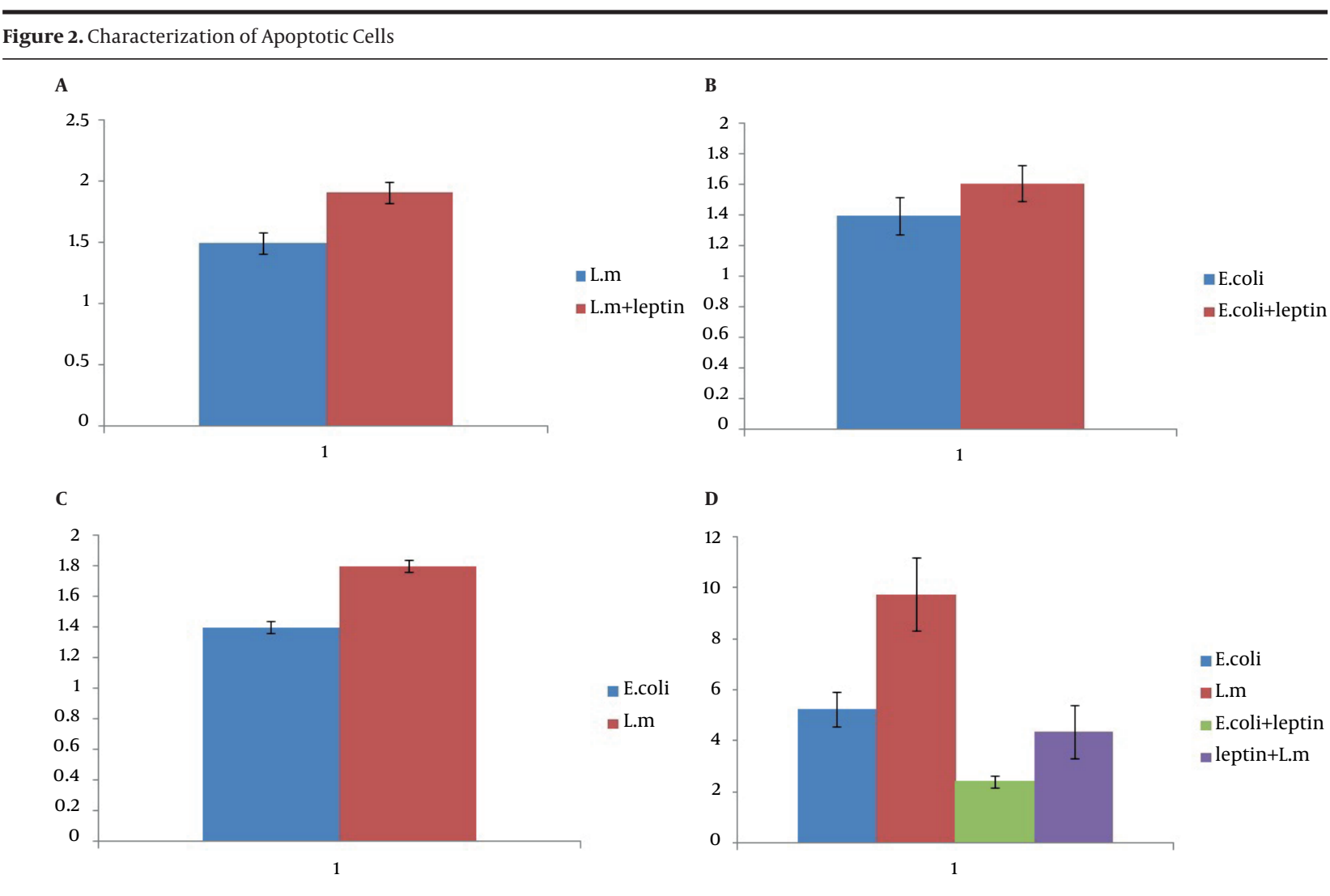

This Figure represents apoptosis rate in Lymphocytes without treatment. The percentage of viable, apoptotic, necrotic and apoptotic + necrotic cells are $90.80 \%, 8.87 \%, 0.27 \%$ and $0.06 \%$, respectively (Figure-4).

After treatment of cells according to Table 2, cells were incubated in thermomixer for $10 \mathrm{~min}$ at $37^{\circ} \mathrm{C}$. Allowing the inoculated bacteria to exert their effects on cells, cells were incubated for $24 \mathrm{~h}$ at $37^{\circ} \mathrm{C}$. Doxorubicin, Germany (50 mg/25 mL) was used as a positive control for induction of cell apoptosis. All experiments were repeated 12 times. For analysis of apoptosis, cells were incubated with FITCconjugated Annexin V (BD Pharmingen, USA) and PI (BD Pharmingen, USA) for $30 \mathrm{~min}$ at $40^{\circ} \mathrm{C}$ and were analyzed by flow cytometry (Partec PAS, Germany), data were analyzed using Flow Max software. For statistical analysis, t-test via SPSS v.17 was used. The list of treatments for apoptosis is demonstrated in Table 2.

\section{Results}

\subsection{Effects of Leptinon CD11b Expression}

CD11b expression on the surface of peripheral blood neutrophils indicates the occurrence of phagocytosis leading to neutrophil stimulation. Data in Figure 1 show the expression of CD11b after various treatments.After 24 h, $0.27 \%, 8.87 \%$ and $90.80 \%$ of non-treatedlymphocytes were apoptotic, necrotic and viable, respectively (Figure 2).

\subsection{Effects of Leptin on Induction of Apoptosis}

In Doxorubicin treated cells (as a control), after $24 \mathrm{~h}$, $43.04 \%$ and 53.60 of cells were apoptotic and viable, respectively. Doxorubicin potently induced apoptosis in treated cells. The percentage of apoptotic cells treated with leptin, E. coli and L. monocytogenes were $2.62 \%$, $4.43 \%$ and $7.94 \%$, respectively, after 24 h. L. monocytogenes induced apoptosis more potent than leptin and $E$. coli $(\mathrm{P}<0.05)$. Cell treated with leptin and L. monocytogenes after $24 \mathrm{~h}$ showed less apoptosis rate (4\%) than only $L$. monocytogenes treated cells $(\mathrm{P}<0.05)$.

Table 3 demonstrates the rate of apoptosis induction on lymphocytes after various treatments. Data in Figure 3 indicates the rate of apoptosis in neutrophils treated with L. monocytogenes , E. coli , leptin + L. monocytogenes and leptin+ E. coli and E. coli , E. coli + Leptin, L. monocytogenes and L. monocytogenes + leptin. Figures 3 and 4 illustrate the percentage of apoptosis, necrosis, apoptosis and necrosis and viability of cells treated with L. monocytogenes , E. coli, leptin + L. monocytogenes, leptin + E. coli and E. coli 
Morshedi A et al.

, leptin+ L. monocytogenes and L. monocytogenes .

Table 3. The Mean Phagocytosis Rate in Leukocytes After Treatment With Leptin, Leptinand E. coli, and Leptin and L. monocytogenes

\begin{tabular}{ll}
\hline Treatment & Apoptosis, Four Replicates \\
\hline E. coli & $5.2675 \%$ \\
L.monocytogenes & $9.7825 \%$ \\
Leptin plus E. coli & $2.4275 \%$ \\
\hline Leptin plus L.monocytogenes & $4.3775 \%$ \\
\hline
\end{tabular}

Figure 3. CD11b Expression After Various Treatments
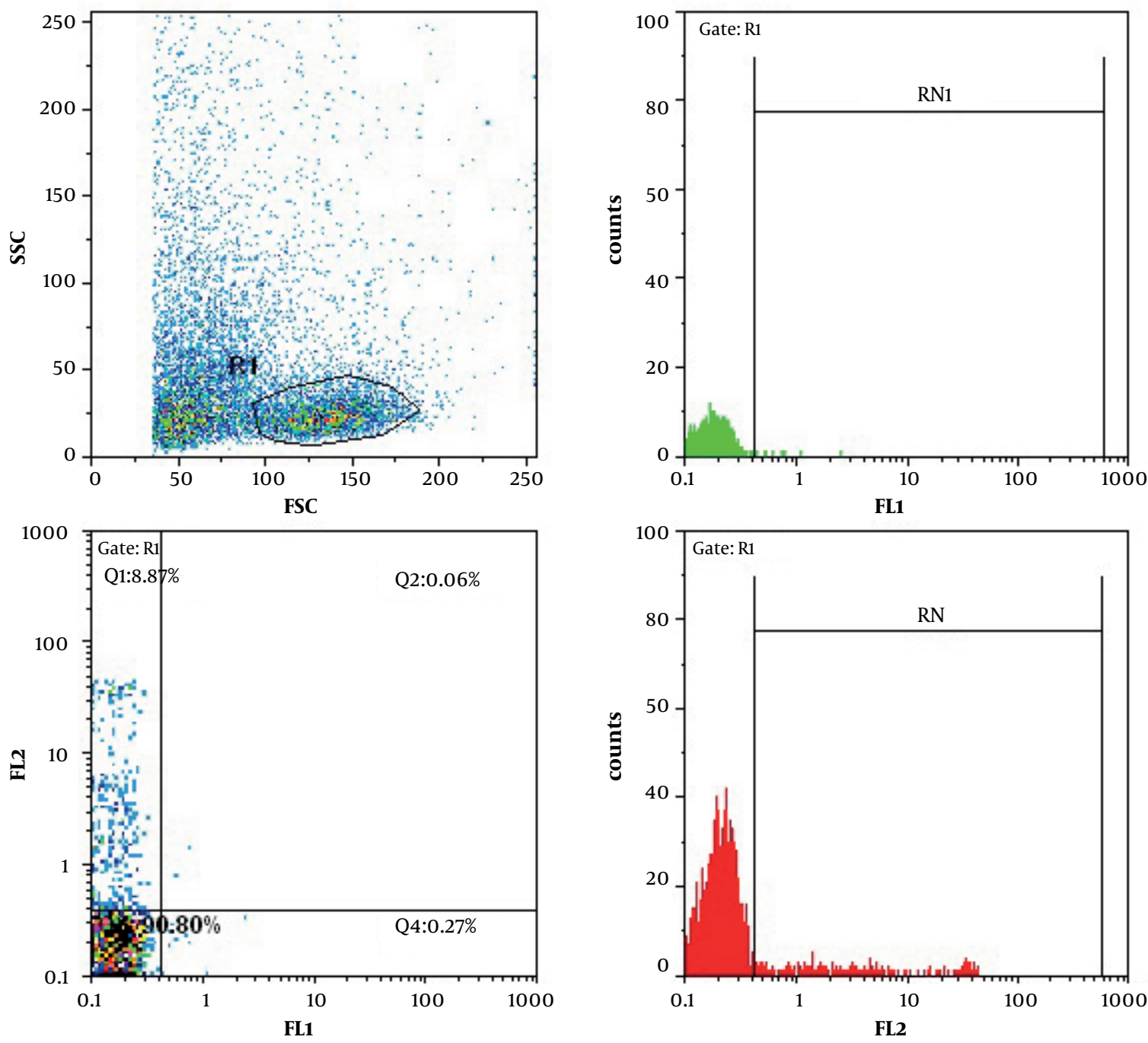

This graph demonstrates CD11b expression on the surface of neutrophils treated with a- L. monocytogenes and E. coli (as a control), b- Leptin+ E. coli and $E$. coli, c- Leptin+L.monocytogenes and L. monocytogenes, d- E. coli, E. coli + Leptin, L. monocytogenesand L. monocytogenes + Leptin. Data are expressed as Mean \pm SD. * indicates statistically significant difference in phagocytosis between two groups $(\mathrm{P}<0.05)$. The $\mathrm{X}$ axis shows two different bacteria and the $\mathrm{Y}$ axis demonstrate the Mean Fluorescent Intensity (MIF) of Cd11b expression. Data are derived from six replicates. 

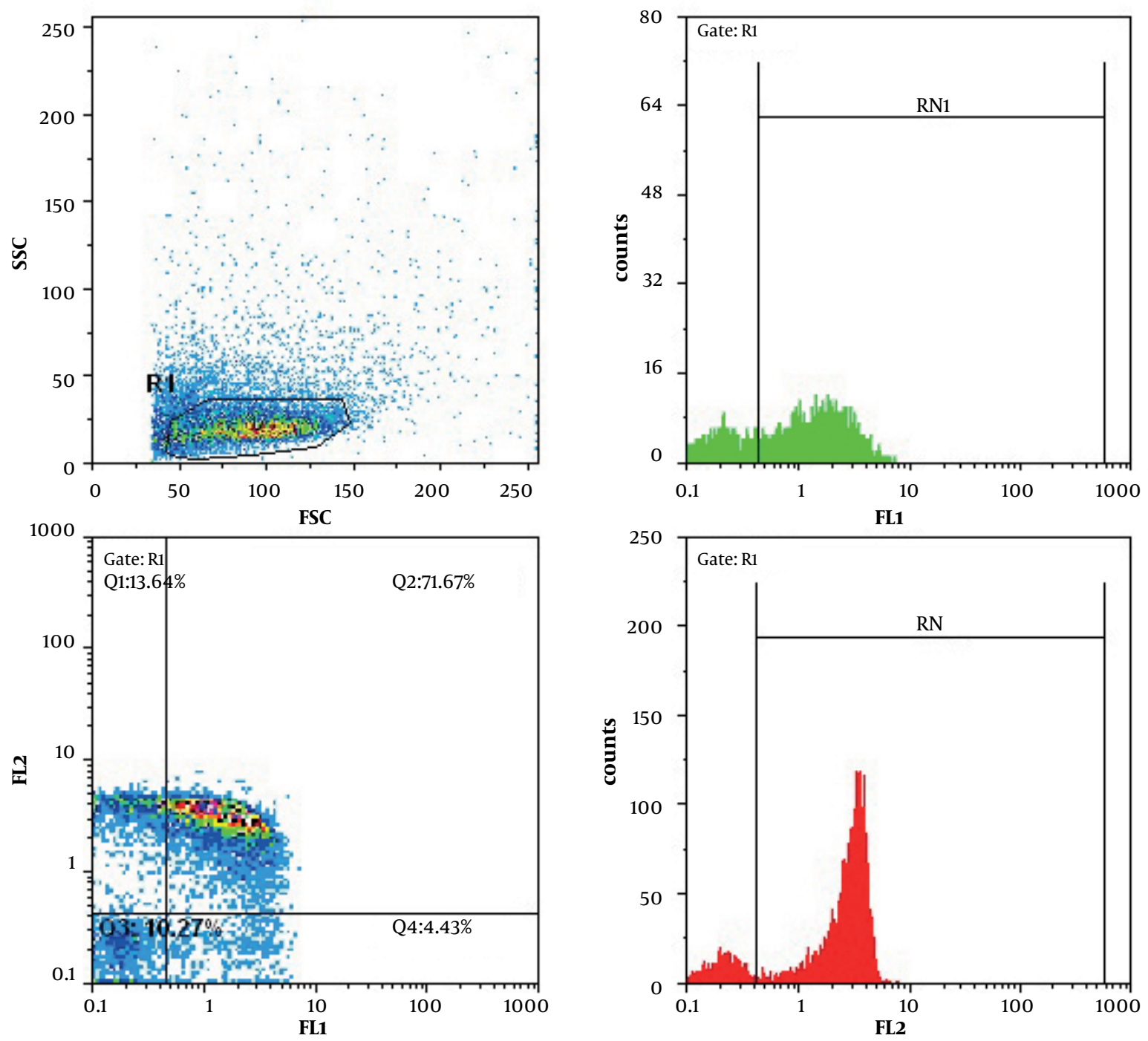

Figure 4. Characterization of Apoptotic Cells

\section{Discussion}

The major finding of this investigation is that L. monocytogenes enhances the neutrophilic phagocytosis more than E. coli. L. monocytogenes is an intracellular pathogen which is able to escape from immune systemand phagosomes through secretion of Listeriolysin. The principal cause of enhanced CD11b expression is the neutrophil stimulation by this toxin. The mechanism of apoptosis by Listeriolysin has been demonstrated to be mediated by CR3-receptor (CD11b and CD18) which play the principal role in bacterial eradication $(15,16)$. The potent stimulation of phagocytosis by L. monocytogenes compared with E. coli, based on our data, is due to its ability to stimulate CD11b expression more effectively than E. coli. Regarding bacterial phagocytosis, our data demonstrates enhanced neutrophilic phagocytosis and CD11b expression on the surface of neutrophils stimulated by L. monocytogenes and E. coli.

Leptin involves in modulation of neutrophilic phagocytosis after binding to Ob-R receptor expressed on the surface of neutrophils (5). Leptin stimulates neutrophils and enhances accumulation of reactive oxygen within neutrophilicphagosomes $(5,17)$. In this way, leptin enhancesneutrophilic phagocytosis $(18,19)$. Leptin actively participates in formation of phagosomes through stimulation of actin polymerization and modulation of actinomyosine interaction (20). Knock-out mice for leptin hormone, showed defective phagocytosis responses to Klebsiella pneumonia. Neutrophils in complement-rich and leptin-deficient environment showed a decreased expression of CD11b which became normalized by leptin treatment (4).

Leptin role in induction of phagocytosis is CD11b-de- 
Morshedi A et al.

pendent. Leptin deficiency is associated with enhanced susceptibility to bacterial infection (21). Zarkesh-Esfahani et al. have demonstrated that leptin, by itself, was not able to stimulate CD11b expression on the surface of neutrophils,while addition of monocytes to neutrophils enhanced CD11b expression in the presence of leptin through stimulation of neutrophils by secreted TNF- $\alpha$ (6). Then, leptin can be used to enhance neutrophilic phagocytosis in bacterial infections such as L. monocytogenes. Leptin enhanced phagocytosis of L. monocytogenes more potent than E. coli.

Induction of apoptosis in murine lymphocytes by $L$. monocytogenes has been demonstrated by Carro et al. in which Listeriolysin $\mathrm{O}$, as a virulent factor, has been considered todirectly induce apoptosis at very low concentrations (22). Injection of L. monocytogenes into mouth, caused wound creation in lymphatic tissue and aggregation of macrophages and neutrophils accompanied by dramatic decrease in the number of $\mathrm{T}$ lymphocytes (23). The data demonstrate that L. monocytogenes induced apoptosis more potent than E. coli, which is compatible with previous reports. This might be due to the presence of apoptotic factor Listeriolysin O, which is absent in $E$. coli. In control lymphocytes only treated with leptin, attenuated lymphocytic apoptosis was observed. Leptin has been shown to decrease lymphocyte apoptosis rate through inhibition of FAS-directed apoptosis pathway (24).

B-cell lymphocytes are more susceptible to induce the apoptosis by leptin related to greater expression of leptin receptor on their surface compared with T-cell lymphocytes (24). Continuous leptin injection into the starved mice has been associated with decreased lymphocyte loss through inhibition of cell apoptosis (25). Leptin injection into mice with enhanced lymphocyte apoptosis as a consequence to steroid administration, has reversed the process (25). Induced lymphocytic apoptosis by leptin is implicated in potentiating immune defense against virulent pathogens. Our data regarding the effects of leptin on induction of apoptosis is compatible with previous findings. Interestingly, our data demonstrates accentuated apoptosis induction after treatment of L. monocytogenes activated lymphocytes by leptin.

Leptin can be used as a potent agent for an effective induction of bacterial phagocytosis and lymphocytic apoptosis in the cases with sever immune-deficiency. It can also be used for the treatment of severe and intractable $L$. monocytogenes and E. coli infections.

\section{Acknowledgements}

None declared.

\section{Authors' Contribution}

Amir Morshedi was MSc student and performed the practical part of the work. S. H. Zarkesh-Esfahani was the supervisor and supervised the whole project. Mohad- deseh Behjati helped with the data analysis and preparation of the manuscript.

\section{Financial Disclosure}

Authors have no conflict of interests.

\section{Funding/Support}

The work was supported financially by the office of Graduate Studies of University of Isfahan. Authors are grateful for the support.

\section{References}

1. La Cava A, Matarese G. The weight of leptin in immunity. Nat Rev Immunol. 2004;4(5):371-9.

2. Chan JL, Moschos SJ, Bullen J, Heist K, Li X, Kim YB, et al. Recombinant methionyl human leptin administration activates signal transducer and activator of transcription 3 signaling in peripheral blood mononuclear cells in vivo and regulates soluble tumor necrosis factor-alpha receptor levels in humans with relative leptin deficiency.J Clin Endocrinol Metab. 2005;90(3):1625-31.

3. Farooqi IS, Matarese G, Lord GM, Keogh JM, Lawrence E, Agwu C, et al. Beneficial effects of leptin on obesity, T cell hyporesponsiveness, and neuroendocrine/metabolic dysfunction of human congenital leptin deficiency. J Clin Invest. 2002;110(8):1093-103.

4. Moore SI, Huffnagle GB, Chen GH, White ES, Mancuso P. Leptin modulates neutrophil phagocytosis of Klebsiella pneumoniae. Infect Immun . 2003;71(7):4182-5.

5. Fernandez-Riejos P, Najib S, Santos-Alvarez J, Martin-Romero C Perez-Perez A, Gonzalez-Yanes C, et al. Role of leptin in the activation of immune cells. Mediators Inflamm. 2010;2010:568343.

6. Tian Z, Sun R, Wei H, Gao B. Impaired natural killer (NK) cell activity in leptin receptor deficient mice: leptin as a critical regulator in NK cell development and activation. Biochem Biophys Res Commun. 2002;298(3):297-302

7. Economou M, Karyda S, Kansouzidou A, Kavaliotis J. Listeria meningitis in children: report of two cases. Infection. 2000;28(2):121-3.

8. Portnoy DA, Auerbuch V, Glomski IJ. The cell biology of Listeria monocytogenes infection: the intersection of bacterial pathogenesis and cell-mediated immunity. J Cell Biol. 2002;158(3):40914.

9. Birmingham CL, Canadien V, Kaniuk NA, Steinberg BE, Higgins $\mathrm{DE}$, Brumell JH. Listeriolysin O allows Listeria monocytogenes replication in macrophage vacuoles. Nature. 2008;451(7176):350-

10. Carrero JA, Calderon B, Unanue ER. Listeriolysin O from Listeria monocytogenes is a lymphocyte apoptogenic molecule. J Immunol. 2004;172(8):4866-74.

11. Zychlinsky A, Sansonetti P. Perspectives series: host/pathogen interactions. Apoptosis in bacterial pathogenesis. J Clin Invest. 1997;100(3):493-5.

12. Leib SL, Kim YS, Chow LL, Sheldon RA, Tauber MG. Reactive oxygen intermediates contribute to necrotic and apoptotic neuronal injury in an infant rat model of bacterial meningitis due to group B streptococci.J Clin Invest. 1996;98(11):2632-9.

13. Savill J. Phagocyte recognition of apoptotic cells. Biochem Soc Trans. 1996;24(4):1065-9.

14. Carrero JA, Unanue ER. Lymphocyte apoptosis as an immune subversion strategy of microbial pathogens. Trends Immunol. 2006;27(11):497-503.

15. Gordon DL, Rice JL, McDonald PJ. Regulation of human neutrophil type 3 complement receptor (iC3b receptor) expression during phagocytosis of Staphylococcus aureus and Escherichia coli. Immunology.1989;67(4):460-5.

16. Abbas KA, Lichtman AH, Pober JS. Cellular and Molecular Immunology. W.B. Saunders Company; 1997. ISBN 13: 978-0721600086.

17. Caldefie-Chezet F, Poulin A, Tridon A, Sion B, Vasson MP. Leptin: a potential regulator of polymorphonuclear neutrophil bacteri- 
cidal action? J Leukoc Biol. 2001;69(3):414-8.

18. Mancuso P, Gottschalk A, Phare SM, Peters-Golden M, Lukacs NW, Huffnagle GB. Leptin-deficient mice exhibit impaired host defense in Gram-negative pneumonia. J Immunol. 2002;168(8):401824.

19. Shirshev SV, Orlova EG. Molecular mechanisms of regulation of functional activity of mononuclear phagocytes by leptin. Biochemistry (Mosc). 2005;70(8):841-7.

20. Attoub S, Noe V, Pirola L, Bruyneel E, Chastre E, Mareel M, et al Leptin promotes invasiveness of kidney and colonic epithelial cells via phosphoinositide 3-kinase-, rho-, and rac-dependent signaling pathways. FASEB J. 2000;14(14):2329-38.

21. Zarkesh-Esfahani H, Pockley AG, Wu Z, Hellewell PG, Weetman AP, Ross RJ. Leptin indirectly activates human neutrophils via induction of TNF-alpha. J Immunol. 2004;172(3):1809-14.

22. Tian Z, Sun R, Wei H, Gao B. Impaired natural killer(NK) cell activity in leptin receptor deficient mice: leptin as a critical regulator in NK cell development and activation. Biochem Biophys Res Commun. 2002;298(3):297-302.

23. Lord GM, Matarese G, Howard JK, Baker RJ, Bloom SR, Lechler RI. Leptin modulates the T-cell immune response and reverses starvation-induced immunosuppression. Nature. 1998;394(6696):897-901.

24. Merrick JC, Edelson BT, Bhardwaj V, Swanson PE, Unanue ER Lymphocyte apoptosis during early phase of Listeria infection in mice. Am J Pathol. 1997;151(3):785-92.

25. Papathanassoglou E, El-Haschimi K, Li XC, Matarese G, Strom T, Mantzoros C. Leptin receptor expression and signaling in lymphocytes: kinetics during lymphocyte activation, role in lymphocyte survival, and response to high fat diet in mice. J Immunol. 2006;176(12):7745-52.

26. Fujita Y, Murakami M, Ogawa Y, Masuzaki H, Tanaka M, Ozaki S, et al. Leptin inhibits stress-induced apoptosis of T lymphocytes. Clin Exp Immunol. 2002;128(1):21-6. 